\title{
21
}

\section{DIGITAL CARE SPACES}

\section{The Particularities of a Digital Home Care Platform}

\author{
Eva Mos
}

\section{Introduction}

As many previous studies have highlighted, the reorganization of traditional welfare states toward so called 'post-welfare' states is characterized by myriad governmental changes, such as marketization, privatization, budget cuts, outsourcing, public-private partnerships, and a renewed focus on familial and community responsibility (Cooper 2017; Ilcan and Basok 2004). Furthermore, welfare state restructuring has been accompanied by changing scales of (social) policy intervention, bringing forth localization and decentralization (Theodore 2019), and renewed attention for proximity and the home (Duyvendak 2011).

To elaborate upon the spatial dimension of these processes, previous scholars have discussed the notions of 'geographies of care' (Lawson 2007) and 'landscapes of care,' pointing at "the complex embodied and organizational spatialities that emerge from and through the relationships of care" (Milligan and Wiles 2010: 740). These authors pay attention to the multiscalar nature of these landscapes, arguing that care and care relationships take place through interconnected scales, stretching from the local to the national and the global. This insight plays a central role throughout this chapter, yet these authors have generally neglected to include a 'digital' dimension of care spatialities. For their part, scholars examining 'welfare technologies' (Hofmann 2013) do centralize the role of (digital) technology but lack engagement with its spatial nature as well as the surrounding political context in which these technologies are at work.

To close these gaps, this chapter will deploy the notion of 'digital care spaces' by examining the operation of the digital home care platform Betreut.de in Germany. On the one hand, the chapter zooms in on the spatial dimensions of this platform, exploring how this digital care space conflates local and global dimensions, appearing close-to-home by locally brokering home care, but simultaneously engaging in global financial and political alliances taking place in the background and out of sight for customers. On the other hand, the chapter positions the platform within debates on the privatization of care, manifested both as the allocation of care responsibilities to private enterprises and to private (family) networks.

In the theoretical section that follows, it is first described how a double process of privatization is at work in the care sector, along with some of its potential pitfalls. Afterward, attention is 
shifted to the spatial nature of care, highlighting how care and care transformations have sedimented in particular geographical spaces as well as providing room for new digital care spaces. In the empirical section, one such digital care space-the home care platform Betreut.deis analyzed. Particular attention is given to how this digital care space conflates local and global dimensions, and how it responds to dilemmas surrounding 'familial privatization' of care. The empirical material presented in this chapter is based on in-depth qualitative interviews with two Betreut.de employees, ten platform users (both platform workers and families), and online research on the platform interface and its online magazine (see Betreut.de 2020a).

\section{A Double Process of Privatization}

A first and most common understanding of privatization highlights the delegation of once governmental services to the private sector, more specifically to private enterprises operating on a market. ${ }^{1}$ In the care sector, this is regularly defined as the 'marketization' or 'commodification' of care, referring to an increased role of private enterprises responsible for the provision and mediation of care services, as well as changes in financial means and subsidies and the growth of cash programs (Ungerson 2003). These processes do not necessarily imply the complete absence of public actors or responsibility, as the "commodification of care has gone hand in hand with an increase in public coverage and public regulation" (Pavolini and Ranci 2008: 247) and has also led to new partnerships between public and private agencies.

One principal mechanism underlying this form of privatization is the introduction of competition. This opens up the care sector for new private providers, as well as encouraging competition among and between private and public care providers. In Germany, this has meanwhile led to $65.8 \%$ of ambulatory care being provided by private companies since their arrival in $1995 .^{2}$ A process of competition is regularly assumed to lead to a diversification of care providers and a pluralization of care options for 'informed' consumers on the market. Care recipients are ideally able to choose from a wide range of care options, in which competition brings forth the best quality services at the least costs (Wiles and Rosenberg 2003). In reality, however, citizens are not always well informed. Furthermore, although the care market is in theory open to everyone, inexperienced or opportunistic players, sometimes referred to as 'care cowboys' (Van der Linden and Spanjers 2019), may turn care into an object of investment in and of itself. Relatedly, in contrast to the expectation of pluralization and diversification, market mechanisms can stimulate monopolistic tendencies, whereby several big providers take over disproportionate segments of the care sector (Stalinski 2018).

Another mechanism accompanying the marketization of care is the establishment of new (semi) market arrangements, such as public-private partnerships. Public-private partnerships are generally characterized by a process of 'contracting out,' in which public agencies contract with private care providers. Care services are carried out by private providers but paid for with public money, also known as the separation of purchaser and provider (Ungerson 2003). Problematically, however, these contracting processes regularly do not work with unlimited budgets, nor work according to the necessities of demand, or the amount of care that is necessary. Rather, a growing demand for care in combination with limited public finances provided for these services lead to shortages in the availability and capacity of care providers, and accordingly problems in the allocation of care, in particular home care. Public officials thereby see themselves confronted with either assigning specialized care to a small group or providing limited care to a larger group (Wiles and Rosenberg 2003). 
When public (home) care services are insufficient or limited, informal and family carers are increasingly called upon to replace or complement formal care provision. The process of privatization of providers is therefore a second form of privatization known as 'familial privatization' or the 'privatization of dependency' (Crossman 2005). For Brenda Crossman (2005: 418), this process of "delegating public goods and services to the family" is legitimized by several morally and fiscally conservative justifications. Fiscal conservatives see the expansion of family rights and obligations as a welcome solution to a minimalist welfare state, whereas social conservatives praise "return to the traditional family and the sanctity of marriage" (ibid.: 420). The re-appraisal of familial responsibility is, however, not only advocated by conservatives, but fits equally well within neoliberal discourses on self-responsibility and welfare state retrenchment (Cooper 2017).

When care provision becomes less secured through public institutions and more dependent on familial circumstances, it also provides room for those families who can afford it to turn to private pay solutions. The two processes of privatization thus collide in those moments where private providers offer individualized and direct care solutions that are (partly) paid for with private money or private insurances, rather than contracting with public administrations. Opportunities arise for 'segmented markets of care,' allowing those with generous pensions or financial backing from family members the possibility of individualized and tailor-made care. In Germany, for example, there has been the appearance of '24-hour care' [24-Stunden-Pflege] in which individual care workers - predominantly migrants from Eastern Europe-reside in seniors' households around the clock. Another option is flexible in-home care by an 'everyday companion' [Alltagsbegleiter], paid by the hour, who delivers companionship, groceries, or cooking. Often, these private pay home care services are characterized by highly individualized and consumer-directed care, "that allow service users and their families to directly hire/ fire and supervise individual home care workers of their choosing” (Doty 2017: 113).

As the empirical section below also demonstrates, these forms of highly individualized care are available for some, but out of reach for others. Furthermore, with individualized and localized approaches to care, provision may become prone to local variation, happenstance, and destabilization on the part of what care is delivered and who delivers it (Wiles and Rosenberg 2003).

\section{New Care Spaces}

For some, the introduction of new home care and family arrangements led to deinstitutionalization, understood as the evaporation of institutional care (Anttonen and Karsio 2016). In this chapter, however, it is considered more useful to examine how new institutions become responsible for care and, as is discussed below, how this is accompanied by new (digital) spaces through which care is provided. While analyses of changing welfare and care regimes regularly emphasize changing policies and discourses, only a few authors have emphasized the spatial element of welfare state restructuring, highlighting how these processes have consolidated or 'sedimented' in particular geographical spaces (Katz 2001). By centralizing place and space, these authors add to the discussion attention to the formation of (new) spaces for social policy and care, such as 'landscapes of care' (Milligan and Wiles 2010), 'geographies of care' (Lawson 2007), and '(counter-)topographies of social reproduction' (Katz 2001).

At the most general level, Cindi Katz (2001) argues that processes of purported 'footloose' or 'vagabond' capitalism are always accompanied by place-bound processes of social 
reproduction, which materialize in particular spaces. She raises awareness of "neglected and undersupported landscapes [...] [such as] schools, playgrounds, parks, and public spaces as well as underfunded or disinvested sites of housing, infrastructures and service provision" (ibid.: 715). Other studies define care spaces more narrowly and focus on particular services or target groups, such as geographies of eldercare, or micro-landscapes of care such as the hospital room or the home (Wiles 2005).

Christine Milligan and Janine Wiles (2010: 740) define landscapes of care as "the complex, embodied, and organizational spatialities that emerge from and through the relationships of care." For them, these landscapes are not one-dimensional and limited to physically demarcated places, but instead multilayered and multiscalar. For example, political-economic developments at the macro level influence who, where, to what extent, and in what way people are cared for. These concern monetary transfers such as subsidies, cash programs, and funding measures (Pavolini and Ranci 2008; Ungerson 2003), but also ideologies and cultural values regarding appropriate approaches to caring, such as prioritizing prevention over cure and independency over dependency (Tronto 2010).

In other words, this means that there are "interconnected scales at and through which care takes place" (Milligan and Wiles 2010: 749). Care is often associated with a local and proximate nature, but may simultaneously relate to the global, for example, where it concerns international care migration or global tech companies intervening in the provision and mediation of care. In the remainder of this chapter, I follow these authors by paying attention to the blurred boundaries between proximity and distance and to examine care "beyond the near familiar" (Lawson 2007: 6). In the section below, it is first shown how the digital home care platform Betreut.de interweaves the local and the global. Afterward, I analyze how the platform responds to dilemmas around the familial privatization of care, by displaying and providing the possibility of individualized private pay care.

\section{Digital Care Spaces: The Particularities of a Digital Home Care Platform}

While some scholars engaged with geographies of care mention the role of new technologies, these often remain a side issue and limited to the role of remote communication and surveillance technologies enabled by smart sensors, robots, or other monitoring devices. Instead, I want to develop the notion of 'digital care spaces' by examining the particularities of the digital home care platform Betreut.de.

Home care platforms can be understood as digital marketplaces that broker basic medical or social in-home care by algorithmically bringing together families and care workers. Such platforms are thus primarily spaces where care is 'mediated' rather than provided. These platforms are not operating according to 'on-demand' models (like Uber), in which the algorithm automatically dispatches workers to consumers, but rather "impact the hiring process through sorting, ranking, and rendering visible large pools of workers" (Ticona et al. 2018: 3). Families looking for care workers scrutinize the platform by being able to select particular characteristics such as distance, gender, language, and personal characteristics as (non-)smoking or affinity with pets.

Betreut.de is a major care platform operating in Germany, but as will be further discussed below, is also part of the global platform company Care.com. Betreut.de was founded in 2007, 
preceding in time major platform companies such as Airbnb and Uber, which only launched in 2008 and 2009 respectively. As Betreut.de is not part of or subsidized by public care programs, it is a privately operating company that is reliant on private money flows. Their business model includes a combination of venture capital investments, client-based subscriptions, and additional partnerships with firms or care institutes. In 2016, the parent company, Care.com, raised considerable amounts of venture capital investment, reaching a total of $\$ 157$ million including a \$46.4 million investment from Alphabet Inc. (Care.com 2016). Betreut.de also earns money through user fees: It allows basic searches and job posts for free but demands a subscription fee to arrange further contact or to become a premium member and thus to appear higher in the list of search results. This membership currently costs $€ 38$ for one month, $€ 77$ for three months, and $€ 155$ for one year. In addition to brokering care for individuals, Betreut.de also runs additional sub-units such as Care@Work, which supports companies in finding care workers for their employees; and Care With Care, which matches German care institutions to internationally recruited care workers (Betreut.de 2020b). These additional activities will be further explored in the next sections.

\section{Interweaving Local Appeal and Global Aspirations}

For users of the platform, Betreut.de displays a convincing local look and feel, and provides several tools to localize one's care request. The very first element users encounter when visiting the platform's home page is the text "Gute Betreuung beginnt hier" [Good care starts here], followed by a search field in which to enter a customer's zip code (see Figure 21.1). In the remainder of the subscription and search process, the user zip code continues to be the first piece of identifying information the platform asks for, before entering any other information such as a name or the type of care needed. Having created a profile and searched for a care worker, the customer can further localize the care request by selecting the preferred radius, or the distance between the place of care provision and the location of the care worker. This menu displays a minimum of one kilometer and a maximum of 50 kilometers, suggesting that the customer's care area cannot exceed this distance. Finally, the user is presented with the average local pay rate, including the hourly wage that would be standard in the user's region (see Figure 21.2).

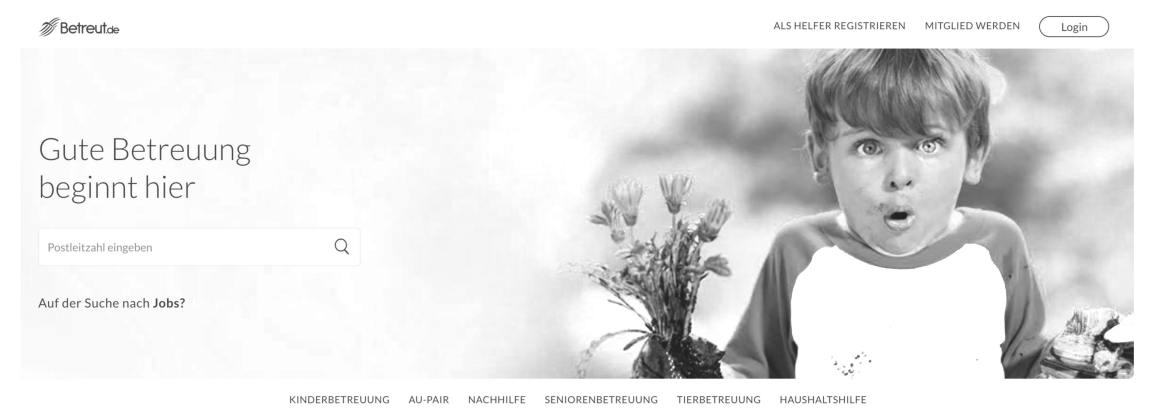

FIGURE 21.1 Screenshot of Betreut.de homepage (www.betreut.de) stating "Gute Betreuung beginnt hier." Source: www.betreut.de, 2020. Reprinted with permission from www .betreut.de. (C2020 Care.com Europe GmbH. All rights reserved. 


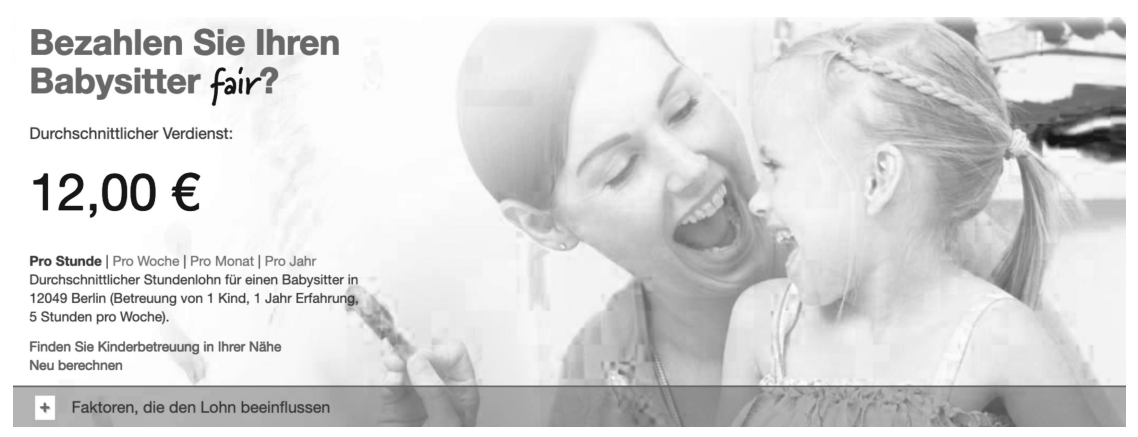

FIGURE 21.2 Screenshot of Betreut.de website (www.betreut.de/stundenlohn-babysitter) presenting the average local pay rate $(€ 12)$ for the zip code 12049 in Berlin. Source: www.betreut .de/stundenlohn-babysitter, 2020. Reprinted with permission from www.betreut.de. (C)2020 Care.com Europe GmbH. All rights reserved.

Apart from the web-based version, Betreut.de is also available through a mobile app. This app has similar features to the web-based version, such as search functions, as well as selection of and chat with care workers. By obtaining the availability for care everywhere and anytime 'in your pocket,' this also entails care workers having to be constantly available for potential requests from families. During an interview, a care worker using the platform interrupted the interview three times to check her phone and reply to messages from families she was working for. She explained that it was very important to answer families quickly, especially if they were potential new customers, since otherwise they might go on and find someone else.

While the platform interface appears highly local to its users, the financial and operational infrastructure behind the platform extends far beyond the local, structurally embedding the platform in networks of global capital and international migration. To start with, Betreut.de is an operating unit of the global platform company Care.com, which operates in over 20 countries and is based in the US. By explicitly aiming to become the "largest online care destination in the world," Care.com took over Betreut.de in 2012 and expressed the "hope to become even more adept at speaking to each market's care challenges and providing a solution for care beyond boundaries" (Care.com 2012). For its part, Care.com is very closely tied to other global stakeholders, most notably to Google Capital, a private equity investor of Google's parent company Alphabet Inc. In 2016 Google Capital became Care.com's main shareholder, as was stated in a press release:

Google Capital, a growth equity fund backed by Alphabet Inc. [...] has made a $\$ 46.35$ million investment in the Company, which makes Google Capital the largest shareholder in Care.com. Laela Sturdy, a Partner at Google Capital, will join Care.com's Board of Directors.

(Care.com 2016)

In its alignment with Google Capital, Care.com is very explicit about its aim of further expansion of the business and "building a global marketplace for care" (ibid.). The aim of private growth is sustained here by seeking the allignment with another major private company, 
Google Capital, in order to have access to "significant operating and investing experience" and further build on "their market leadership" (ibid.). In contrast to public-private partnerships, a bridge is built here between two private entities. Rather than highlighting how this collaboration improves the quality of care delivered, or how their platform attempts to make care more accessible, the goal of growth and competitive advantage as a goal in itself is remarkable, boasting its monopolistic tendencies to become the primary online destination of care throughout the world (ibid.).

As a second instance of its global reach, Betreut.de is also embedded in international processes of internal care migration through its business unit Care With Care. Care With Care is, as an employee described it in an interview, a spin-off that is involved in recruiting, training, and mediating foreign health-care workers for German care institutions. Care workers are predominantly recruited from the Philippines, which is considered by Betreut.de as "the world's largest exporter of caregivers" and is confronted with "300,000 unemployed care workers" (Esnaola 2017: 4, own translation). To recruit and educate care workers, Betreut. de collaborates with a local recruitment agency that selects and trains the potential workers according to German qualification standards and teaches them university-level German. Furthermore, Care With Care facilitates the arrangement of German work permits and visa processes.

With this business unit, Betreut.de is very explicit in its global aspirations, stating that "Care With Care aims to offset the global nursing imbalance by connecting un- or under-employed nurses from across the world with healthcare institutions in regions suffering from a staffing shortage" (Care With Care 2020). In particular, they aim to connect the supply of care workers from 'emerging' countries to care shortages in 'developed' nations. This is considered an opportunity both for migrant care workers and their families, as well as for patients and care institutions at the other side of the world:

We know our project will not solve the world's global imbalance of health care staff. However, I believe that we are contributing one important piece of the puzzle as there is a quadruple win: for the nurses and their families, the patients, strained healthcare system, and for our business.

(Esnaola 2017: 7, own translation)

Finally, the aspirations of the global platform Care.com to become the largest online care provider, as well as its involvement in international care migration, highlight the ways in which it is globally embedded. Not only does Care.com aim to become a major and even monopolistic care provider, it also aims to be involved in a global migration infrastructure dedicated to solving Germany's care deficit. While their direct business model - the local brokerage of home care-can easily be deployed in multiple localities due to standardization of the platform interface, its financial and political role extends these localities.

\section{Platform Care as a Response to Familial Privatization}

Bringing back the focus to the everyday, local brokerage of care, the remainder of this chapter shows how Betreut.de responds to dilemmas arising from care responsibilities within the family (referred to earlier as familial privatization). In its external communications and public relations, Betreut.de is very explicit about its role in providing and responding to family-related 
care issues, especially where it concerns women that both want to pursue a career and have a caring responsibility. In the interviews, however, the familial issue that appeared more acute was the absence of grandparents to care for children (in the case of childcare), or the absence of adult children to care for their senior parents (in the case of senior care). Interviews thus particularly revealed forms of intergenerational family care that were lacking and subsequently the motivation to turn to the platform.

From the interviews, two types of platform users appeared: women between 30 and 45 that searched for childcare for their children or senior care for their parents; and seniors that were either childless or had children living far away. An instance of the first group is a mother of two children in her thirties, employed part-time, who points out that many families in the suburban neighborhood where she lives deal with the absence of grandparents. She argues that to live in a very "family friendly neighborhood" (Betreut.de user 1, personal communication, September 2019, own translation) that predominantly accommodates families with young children is to lack the presence of grandparents nearby:

[Our parents] are too far away. Well, that is also a bit of a thing. There are, I think, also here in the region... a bit of the drama of Berlin. Many have moved to Berlin because of their studies. Me, too. And, or work-related, [as] my husband. And in that respect the grandparents live a few hundred kilometers in another direction. And they come over only one, two times per year to visit. And that is the case for many people here in the neighborhood. So, this "grandparents' model" is unfortunately actually quite poor here. And therefore, the people search via whatever channels for care workers, childcare, because the grandmother or so are not available so far away.

Not only in the case of childcare, but also for platform-mediated senior care, the physical distance between adult children and their senior parents was brought up as a reason to use the platform. For example, a woman in her early forties lives in Berlin, while her parents reside approximately five hours outside of Berlin. As her mother was suffering from multiple sclerosis and her father indicated he could not provide the necessary care anymore, she decided to use Betreut.de to find a care worker and give her father some time off. For her, it was clear that she would not provide the care herself, but instead what she could provide, from a distance, was to search online for a care worker that could support her parents. As she explains:

So I didn't want to take over the care, as they're not living in Berlin, but in Chemnitz. That is with the train, also from door to door it is I believe around five hours. And so, first, I couldn't provide care, so to say, due to the distance, and also I wouldn't have wanted it. That is, I don't want to care for my mother. This is too close for me, these are things that I wouldn't want to do. And exactly, then I've said, but what I can do, how I can help you, I can search for things on the internet.

(Betreut.de user 2, personal communication, August 2019, own translation)

The quote above shows a justification to outsource care for senior parents both due to the physical distance, but also because of a desire to refrain from intergenerational care due to moral considerations of avoiding too close an involvement with the care of one's parents. This moral consideration is also something Betreut.de speaks to on its website. By directing their 
attention to family caregivers rather than to seniors per se, family caregivers are encouraged to 'let go,' to 'get help,' and to 'care less' (Lewandowski 2020) by finding a private caregiver through the platform. Betreut.de explicitly address the (emotional) struggles that family caregivers may be confronted with, as well as proposing a suitable solution. In one of the articles in the Betreut.de Magazine people are encouraged to turn "a visit to mum, dad or grandparents into something special rather than an everyday obligation" (ibid.).

As a solution, Betreut.de proposes to outsource these caring responsibilities to care workers easily and flexibly available on their platform. What they announce to offer is a highly individualized, mobile and round-the-clock 'access to care.' The question that thereby remains implicit is who has access to this care in the first place and who can outsource the 'burden' of caring to platform workers. Importantly, the platform-mediated service is a form of private pay care that cannot yet be reimbursed through public care subsidies or public health insurances. In some cases of childcare, employers pay part of the costs or costs can be withdrawn from taxes when parents are self-employed. In the case of senior care, however, my respondents pointed out that their parents had either very generous pensions due to working in high-end jobs during their career, or that the children partly paid for the costs. To what extent this platform-mediated care is thus a sustainable solution where it concerns access to care remains highly questionable. To conclude, the observation of a platform care worker, a woman in her sixties, is very telling when she states that, "the care that I currently provide to these seniors, I would never be able to receive myself" (Betreut.de user 3, personal communication, October 2019, own translation).

\section{Conclusion}

This chapter positioned the operation of digital home care platform Betreut.de within two debates on the privatization of care. On the one hand, Betreut.de's involvement with global finance capital and international migration reveals their aim of becoming a global market leader in the sector of care and displays their ambition of private growth as a goal in itself. On the other hand, the platform responds to local dilemmas rising from the absence of intergenerational family caregivers and is thereby embedded in micro-situations concerning familial privatization of care. By offering an (individualized) market alternative to these dilemmas, it becomes possible - at least for those families who can afford it - to outsource caring responsibilities to flexibly available platform workers.

These digital care spaces are thus spaces that blur boundaries between proximity and distance and show how care becomes a matter beyond 'the near familiar.' In fact, Betreut.de operates above and apart from national welfare states and is thereby not tied to national citizenship rights concerning the accessibility and equal distribution of care. While providing a solution for some-especially more affluent-segments of society, it remains questionable whether these platforms provide a sustainable answer to welfare state restructuring.

\section{Notes}

1 Privatization is regularly also understood as the delegation of services to the 'voluntary' sector. This will not receive further attention in this chapter.

2 This percentage is based on data from the Federal Statistical Office, gathered in 2017 (see Statistisches Bundesamt 2018). 


\section{References}

Anttonen, A. and Karsio, O. (2016) Eldercare Service Redesign in Finland: Deinstitutionalization of Long-Term Care. Journal of Social Service Research 42(2): 151-166.

Betreut.de (2020a) Über Uns: Wir helfen Familien und Betreuungsanbietern, einander zu finden [Online]. Available at https://www.betreut.de/unternehmen- [Accessed 1 June 2020].

Betreut.de (2020b) Betreut.de Magazin [Online].Available at https://www.betreut.de/magazin [Accessed 28 September 2020].

Care with Care (2020) About Us [Online]. Available at https://www.carewithcare.com/about-us [Accessed 4 June 2020].

Care.com (2012, July 11) Care.com Acquires Besser Betreut and Becomes the Largest Online Care Destination in the World. Press Releases [Online]. Available at https://www.care.com/press-releasecarecom-acquires-besser-betreut-p1186-q18393183.html [Accessed 4 June 2020].

Care.com (2016, June 29) Google Capital Invests in Care.Com: Transaction Marks First Investment in Public Company by Google Capital. Press Releases [Online]. Available at https://www.care.com/ press-release-google-capital-invests-in-carecom-p1186-q78109137.html [Accessed 1 June 2020].

Cooper, M. (2017) Family Values: Between Neoliberalism and the New Social Conservatism. Cambridge, MA: MIT Press.

Crossman, B. (2005) Contesting Conservatisms, Family Feuds and the Privatization of Dependency. American University Journal of Gender, Social Policy and The Law 13(3): 415-509.

Doty, P. (2017) Private Pay Home Care: New Models of Access and Service Delivery. Public Policy \& Aging Report 27(3): 111-120.

Duyvendak, J.W. (2011) The Politics of Home: Belonging and Nostalgia in Europe and the United States. New York: Palgrave Macmillan.

Esnaola, L. (2017) Pflege über Grenzen. Harvard Business Manager 12: 1-7 [Online]. Available at http:// cwc2.carewithcare.wpengine.com/wp-content/uploads/sites/40/2018/05/Harvard-BusinessManager_2017_11_Pflege_ueber_Grenzen.pdf [Accessed 28 September 2020].

Hofmann, B. (2013) Ethical Challenges with Welfare Technology: A Review of the Literature. Science and Engineering Ethics 19(2): 389-406.

Ilcan, S. and Basok, T. (2004) Community Government: Voluntary Agencies, Social Justice, and the Responsibilization of Citizens. Citizenship Studies 8(2): 129-144.

Katz, C. (2001) Vagabond Capitalism and the Necessity of Social Reproduction. Antipode 33(4): 709-728.

Lawson,V. (2007) Geographies of Care and Responsibility. Annals of the Association of American Geographers 97(1): $1-11$.

Lewandowski, K. (2020, May 29) 10 Dinge, die sich ändern, wenn Sie einen Seniorenbetreuer einstellen. Betreut.de Magazin [Online]. Available at https://www.betreut.de/magazin/erwachsene-senioren/9dinge-die-sich-veraendern-wenn-sie-einen-seniorenbetreuer-fuer-ihre-angehoerigen-gefundenhaben [Accessed 30 May 2020].

Milligan, C. and Wiles, J. (2010) Landscapes of Care. Progress in Human Geography 34(6): 736-754.

Pavolini, E. and Ranci, C. (2008) Restructuring the Welfare State: Reforms in Long-Term Care in Western European Countries. Journal of European Social Policy 18(3): 246-259.

Stalinski, S. (2018) Gewinne statt Gemeinwohl: Der Profit mit der Pflege. Tagesschau [Online]. Available at https://www.tagesschau.de/wirtschaft/profite-pflege-101.html [Accessed 7 August 2020].

Statistisches Bundesamt (2018) Pflegestatistik: Pflege im Rahmen der Pflegeversicherung LändervergleichAmbulante Pflegedienste [Online]. Available at https://www.destatis.de/DE/Themen/GesellschaftUmwelt/Gesundheit/Pflege/_inhalt.html\#sprg234062 [Accessed 28 September 2020].

Theodore, N. (2019) Governing Through Austerity: (Il)Logics of Neoliberal Urbanism after the Global Financial Crisis. Journal of Urban Affairs 42(1): 1-17.

Ticona, J., Mateescu, A. and Rosenblat, A. (2018) Beyond Disruption: How Tech Shapes Labor Across Domestic Work and Ridehailing. Data \& Society Report [Online]. Available at https://datasociety. 
net/wp-content/uploads/2018/06/Data_Society_Beyond_Disruption_FINAL.pdf [Accessed 11 May 2019].

Tronto, J.C. (2010) Creating Caring Institutions: Politics, Plurality, and Purpose. Ethics and Social Welfare 4(2): 158-171.

Ungerson, C. (2003) Commodified Care Work in European Labour Markets. European Societies 5(4): 377-396.

Van der Linden, A. and Spanjers, J. (2019, December 16) Gebrekkig toezicht door gemeenten geeft zorgcowboys vrij spel. Follow The Money [online]. Available at https://www.ftm.nl/artikelen/ enquete-gemeenten-zorgcowboys [Accessed 22 November 2020].

Wiles, J. (2005) Conceptualizing Place in the Care of Older People:The Contributions of Geographical Gerontology. Journal of Clinical Nursing 14(2): 100-108.

Wiles, J. and Rosenberg, M.W. (2003) Paradoxes and Contradictions in Canada's Home Care Provision: Informal Privatization and Private Informalization. International Journal of Canadian Studies 28(Fall): 63-89. 
$\because$ Taylor \& Francis Taylor \& Francis Group http://taylorandfrancis.com 